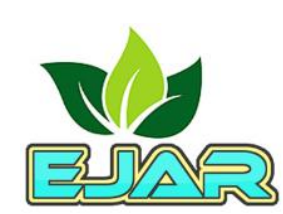

RESEARCH

\title{
Phenotypic and genotypic profiling of Methicillin-resistant Staphylococcus aureus isolates from human and bovine milk
}

\author{
Hala R. Ali ${ }^{1}{ }^{*}$, Naglaa F. Koraney ${ }^{1}$, Esraa G. Hefny ${ }^{2}$, Samah F. Ali ${ }^{1}$, Shymaa R. Abdel Mawgoud ${ }^{1}$ and Essam I. EltouKhy ${ }^{3}$ \\ Address: \\ ${ }^{1}$ Bacteriology Department, Animal Health Research Institute (AHRI), Agriculture Research Center, Giza, 12618, Egypt \\ ${ }^{2}$ Food Hygiene Department, Animal Health Research Institute (AHRI), Agriculture Research Center, Giza, 12618, Egypt \\ ${ }^{3}$ Biotechnology Department, Animal Health Research Institute (AHRI), Agriculture Research Center, Giza, 12618, Egypt \\ *Corresponding author: Hala R. Ali , Email: alihala312@gmail.com \\ Recivied in 10.06.2021; Accepted: 04.07.2021; Published: 18.07.2021 \\ 10.21608/ejar.2021.79959.1115
}

\section{ABSTRACT}

The current work aimed to track the spread of methicillin-resistant Staphylococcus aureus (MRSA) in human and bovine milk in Fayoum city, Egypt. $74 \%$ of isolates obtained from a human with septic sore throat and $40 \%$ of bovine isolates from bulk milk tank were found positive for S. aureus. The typical characteristics of MRSA including resistance to oxacillin and meca positivity were detected in $8 \%$ and $7 \%$ of the human and bovine isolates respectively. The antibiotic resistance profile of human and bovine MRSA isolates have shown a high degree of similarity with complete resistance to beta-lactam antibiotics associated with variable resistance to other antibiotic classes. Nevertheless, $99-100 \%$ identity has been detected between meca gene of the human and bovine isolates and multiple MRSA strains in Genebank. The identified phenotypic and genotypic similarity provides clear evidence of potential epidemiological relation between the human and bovine MRSA isolates. However, further study is required to identify the mode of transmission of MRSA isolates between human and different livestock animals on wide-scale and expand the study to include wild animals.

Keywords: Methicillin-resistant Staphylococcus aureus, septic sore throat, meca gene, Bulk milk tank.

\section{INTRODUCTION}

Methicillin-resistant Staphylococcus aureus (MRSA) is a major public health threat worldwide. However, MRSA infections have only begun in the health care community, a high rate of MRSA was recently observed among people in different communities and have no risk factors for acquiring MRSA infections. This might be attributed to emergence of such infections in livestock and food chain animals. Previous reports provided shreds of evidence for the capability of MRSA to transmit between equines and humans especially veterinarians and workers at veterinary hospitals. The study found that people in contact with horses infected with MRSA showed skin infections caused by horse strain (Weese et al., 2006 and Schwaber et al., 2013). Various companion animals including pets, pigs, rabbits and sheep have been found to host MRSA of human origin, revealing that animals that come into contact with infected personnel may serve as effective reservoirs for spreading the infection widely (Medhus et al.,2013., Haenni et al., 2012, Vincze et al., 2014 and Walther et al., 2012).

Staphylococcus aureus is the major cause of infections in cattle and is associated with significant economic losses in dairy business. The staphylococcal infection has been complicated by reporting first case of MRSA in bovine mastitis in the 1970s, and to date, MRSA isolates have been reported in cattle and milk all over the world (Bardiau et al.,2013). The growing spread of MRSA in cattle and dissemination of this organism in milk highlights the significant importance of MRSA as an emerging zoonotic pathogen and points that further evaluation of interspecies transmission of MRSA is highly required. High phenotypic and genotypic similarities have been previously reported in MRSA isolates from cattle and humans suggesting the possibility of direct transmission of MRSA from cattle to humans and vice versa (Juhász et al., 2007). The current work was undertaken to monitor the prevalence of MRSA in human and bovine milk (bulk milk tank), and to study the phenotypic and genotypic features of bovine and human isolates to track the spread of MRSA strains in Fayoum city, Egypt.

\section{MATERIALS AND METHODS}

1. Isolation and characterization of S. aureus:

1.1. Sampling: The bovine milk samples were collected from bulk tank milk in dairy farms and throat swabs were collected from human admitted to a private bacteriological laboratory. The throat swabs were collected voluntary from human with septic sore throats during routine sampling for bacteriological analysis.

1.2. Bacteriological analysis and characterization (Kümmel et al., 2016): Milk samples and throat swabs were enriched in peptone water $\left(1 \mathrm{ml}\right.$ milk in $9 \mathrm{ml}$ sterile PW) for $48 \mathrm{hr}$ at $37^{\circ} \mathrm{C}$, followed by streaking on selective media (Baird parker) for $24 \mathrm{hrs}$ at $37^{\circ} \mathrm{C}$. The suspected black colonies were then streaked on nutrient agar for $24 \mathrm{hr}$ at $37^{\circ} \mathrm{C}$ and then the primary isolates were analyzed by gram staining. Furtherly, the isolated strains were examined for blood hemolysis and submitted to biochemical characterization including catalase, urease, mannitol and coagulase tests.

2. Antimicrobial susceptibility testing:

all the $S$. aureus isolates including human and bovine isolates were examined by disk diffusion method using oxacillin. Then, oxacillin resistant $S$. aureus were further tested against 16 antibiotics. Briefly, the inoculum suspension was prepared by transferring few colonies from the nutrient agar to sterile saline and the inoculum turbidity was adjusted to a $0.5 \mathrm{McFarland}$ standard. Then, lawn culture of the tested bacterial suspension was 
prepared by spreading few microliters of inoculum on Muller Hinton agar plates. Antibiotic discs were then applied on the cultured agar plate. After overnight incubation at $37^{\circ} \mathrm{C}$, the inhibition zone was measured, and the results were interpreted according to CLSI (Clinical and Laboratory Standards Institute 2009).

3. Molecular characterization of MRSA using PCR (McClure et al., 2006):

3.1. DNA extraction. To extract the DNA, the QIAamp DNA Mini kit is used with slight modifications from the manufacturer's instructions (Qiagen, Germany, $\mathrm{GmbH}$ ). Briefly, $200 \mu$ l of the sample suspension was incubated for 10 minutes with $10 \mu \mathrm{l}$ of proteinase $\mathrm{K}$ plus $200 \mu \mathrm{l}$ of lysis buffer at $56^{\circ} \mathrm{C}$. Following the incubation, $200 \mu \mathrm{l}$ of $100 \%$ ethanol was added to the lysate. The sample mixture was then washed and centrifuged according to the manufacturer's method. The elution of nucleic acid was performed using $100 \mu$ l of elution buffer.

3.2. PCR amplification. The Oligonucleotide primer (Metabion, Germany), listed in Table (1), were used in a $25 \mu \mathrm{l}$ reaction composed of $12.5 \mu \mathrm{l}$ EmeraldAmp Max PCR Master Mix (Takara, Japan), $1 \mu \mathrm{l}$ of each primer (20 pmol), $4.5 \mu \mathrm{H} 2 \mathrm{O}$, and $6 \mu \mathrm{l}$ DNA template. The amplification reaction was conducted in an Applied biosystem 2720 thermal cycler.

3.3. Analysis of the PCR Products. The PCR products were fractionated by electrophoresis using $1.5 \%$ agarose gel (Applichem, Germany, GmbH) in 1x TBE buffer at room temperature using gradients of $5 \mathrm{~V} / \mathrm{cm}$. For gel analysis, $20 \mu \mathrm{l}$ of the PCR products was loaded in each gel slot. A generuler $100 \mathrm{bp}$ DNA ladder (Fermentas, Thermo, Germany) was also loaded to detect the fragment sizes. The gel was imaged by a gel documentation system (Alpha Innotech, Biometra) and the data were then subjected to analysis using computer software.

Table 1: Primers sequences, target genes, amplicon sizes and cycling conditions.

\begin{tabular}{|c|c|c|c|c|c|c|c|c|}
\hline \multirow{2}{*}{$\begin{array}{l}\text { Target } \\
\text { gene }\end{array}$} & \multirow{2}{*}{$\begin{array}{l}\text { Primers } \\
\text { sequences }\end{array}$} & \multirow{2}{*}{$\begin{array}{l}\text { Amplified } \\
\text { segment } \\
\text { (bp) }\end{array}$} & \multirow{2}{*}{$\begin{array}{l}\text { Primary } \\
\text { denaturation }\end{array}$} & \multicolumn{3}{|c|}{ Amplification (35 cycles) } & \multirow{2}{*}{$\begin{array}{l}\text { Final } \\
\text { extension }\end{array}$} & \multirow[t]{2}{*}{ Reference } \\
\hline & & & & Denaturation & Annealing & Extension & & \\
\hline \multirow[t]{2}{*}{ meca } & $\begin{array}{l}\text { GTA GAA ATG } \\
\text { ACT GAA CGT } \\
\text { CCG ATA A }\end{array}$ & \multirow[t]{2}{*}{310} & \multirow[t]{2}{*}{$\begin{array}{l}94^{\circ} \mathrm{C} \\
5 \text { minutes. }\end{array}$} & \multirow[t]{2}{*}{$\begin{array}{l}94^{\circ} \mathrm{C} \\
30 \text { second. }\end{array}$} & \multirow[t]{2}{*}{$\begin{array}{l}50^{\circ} \mathrm{C} \\
30 \\
\text { second. }\end{array}$} & \multirow[t]{2}{*}{$\begin{array}{l}72^{\circ} \mathrm{C} \\
30 \\
\text { second. }\end{array}$} & \multirow[t]{2}{*}{$\begin{array}{l}72^{\circ} \mathrm{C} \\
7 \text { minutes. }\end{array}$} & \multirow[t]{2}{*}{$\begin{array}{l}\text { McClure } \\
\text { et al., } \\
2006\end{array}$} \\
\hline & $\begin{array}{l}\text { CCA ATT CCA } \\
\text { CAT TGT TTC } \\
\text { GGT CTA A }\end{array}$ & & & & & & & \\
\hline
\end{tabular}

\section{Nucleotide sequencing:}

PCR products were purified using QIAquick PCR Product extraction kit. (Qiagen, Valencia). Bigdye Terminator V3.1 cycle sequencing kit(Perkin-Elmer) was used for the sequence reaction and then it was purified using Centrisep spin column. DNA sequences were obtained by Applied Biosystems3130 genetic analyzer (HITACHI, Japan), a BLAST ${ }^{\circledR}$ analysis (Basic Local Alignment Search Tool) (Altschul et al., 1990) was initially performed to establish sequence identity to GenBank accessions. The phylogenetic tree was created by the MegAlign module of LasergeneDNAStar version 12.1 Thompson et al., (1994) and Phylogenetic analyses were done using maximum likelihood, neighbour-joining and maximum parsimony in MEGA6 (Tamura et al., 2013).

\section{RESULTS}

\section{Isolation and Characterization of MRSA:}

50 samples from bulk milk tank and 100 throat swabs from human with septic sore throat, were collected from different villages in Fayoum city during 2017 and 2018. The human with septic sore throat were voluntarily sampled during attending private bacteriological laboratories. Both milk samples and throat swabs were firstly enriched in peptone water then plated on Baird parker. The culture-positive Staphylococcus isolates were furtherly characterized via biochemical tests and hemolysis on blood agar. The $\mathrm{S}$. aureus isolates were characterized as gram-positive cocci, with positive catalase test, positive coagulase tests and showing beta-hemolysis on blood agar.

To detect MRSA strains, the $S$. aureus isolates were first screened by oxacillin disk diffusion method and the result showed that $9(24.3 \%)$ of $S$. aureus isolates recovered from bovine milk and $9(22.5 \%)$ of human isolates exhibited resistance to oxacillin. The molecular method using PCR demonstrates that 4 bovine isolate and 7 human isolates harboring mec A gene and showing the expected band at $310 \mathrm{bp}$ (Figure 1).

As shown in table 1, MRSA prevalence in bovine milk and human samples based on phenotypic identification, was approximately $18 \%$ and $9 \%$ respectively. However, lower incidence rate in (8\%) bovine milk and (7\%) human samples were maintained the typical characteristics of MRSA including resistance to oxacillin and mecA positivity (Table 2).

Table 2: The prevalence of MRSA in human and bovine milk based on oxacillin resistance and harboring of mec $A$ gene.

\begin{tabular}{|c|c|c|c|c|c|c|}
\hline \multirow{3}{*}{\begin{tabular}{|l|} 
Source \\
Bovine milk \\
\end{tabular}} & \multirow{2}{*}{\multicolumn{2}{|c|}{$\begin{array}{l}\text { S. aureus } \\
\text { No Prevalence }\end{array}$}} & \multicolumn{4}{|l|}{ MRSA } \\
\hline & & & \multicolumn{2}{|c|}{$\begin{array}{c}\text { Oxacillin-resistant No } \\
\text { Percentage }\end{array}$} & \multicolumn{2}{|c|}{$\begin{array}{l}\text { mec A gene positive } \\
\text { No Percentage }\end{array}$} \\
\hline & 37 & $74 \%$ & 9 & $18 \%$ & 4 & $8 \%$ \\
\hline Human & 40 & $40 \%$ & 9 & $9 \%$ & 7 & $7 \%$ \\
\hline
\end{tabular}


a)

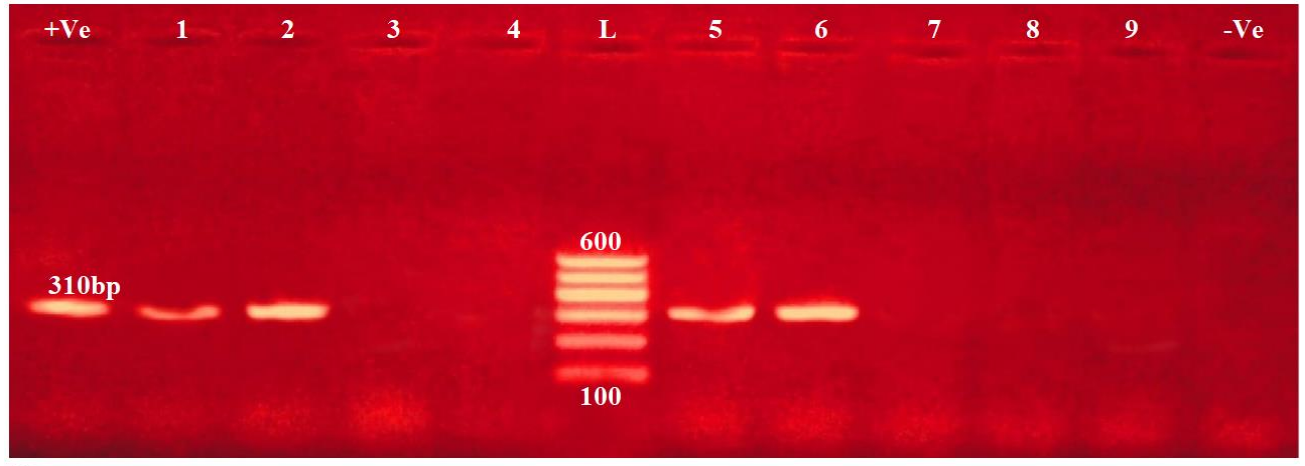

b)

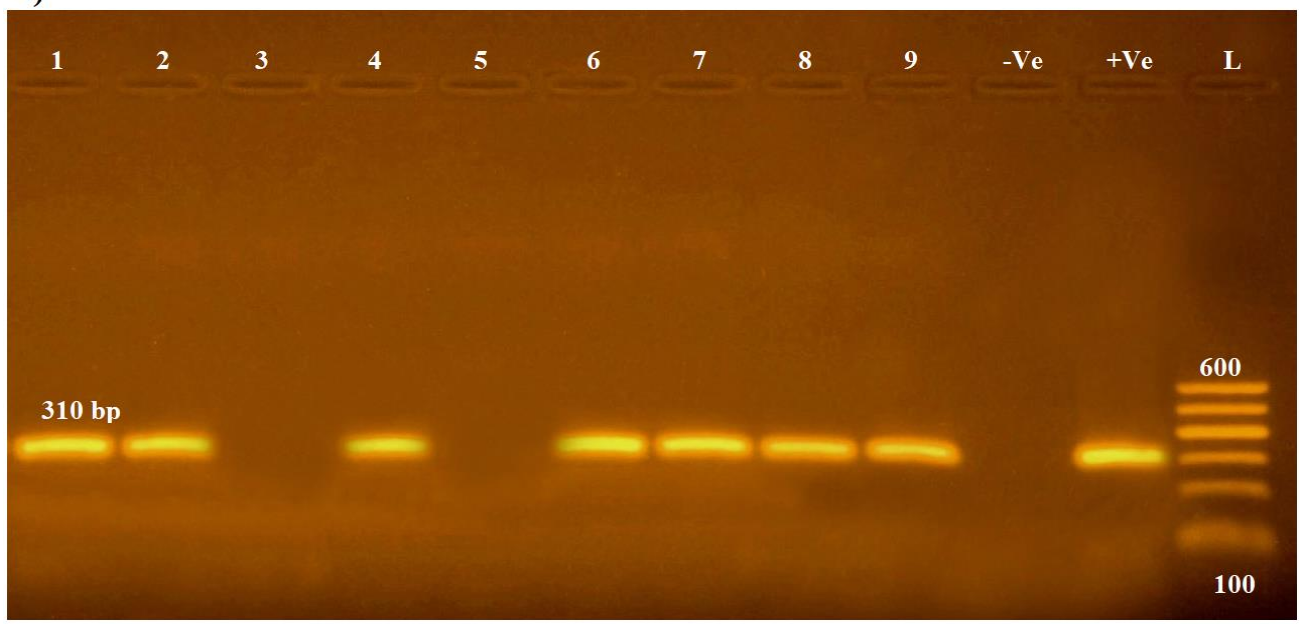

Fig1: PCR amplicon of mec A gene in MRSA isolates with positive band at $310 \mathrm{bp}$. a) MRSA isolates from bovine milk: lane1, 2,5 and 6 are positive, lane $3,4,7,8$, and 9 are negative. b) MRSA isolates from human samples (throat swabs): lane 1, $2,4,6,7,8$ and 9 are positive, while lane 3 and 5 are negative. Lane $+V e$ is control positive, lane - $V e$ is control negative and lane $L$ is DNA ladder.

\section{The antibiotic susceptibility profile of MRSA isolates:}

To determine the antibiotic susceptibility profile of the phenotypically identified MRSA isolates through oxacillin disk diffusion method, the isolates were tested against 13 antibiotics as shown in Figure 2. The results showed that both human and bovine isolates had pronounced resistance to beta-lactam antibiotics, with $100 \%$ resistance to amoxicillin-clavulanic acid and penicillin. Resistance to ampicillin/Sulbactam was observed in $55.5 \%$ of human isolates and $50 \%$ of bovine isolates.

a)

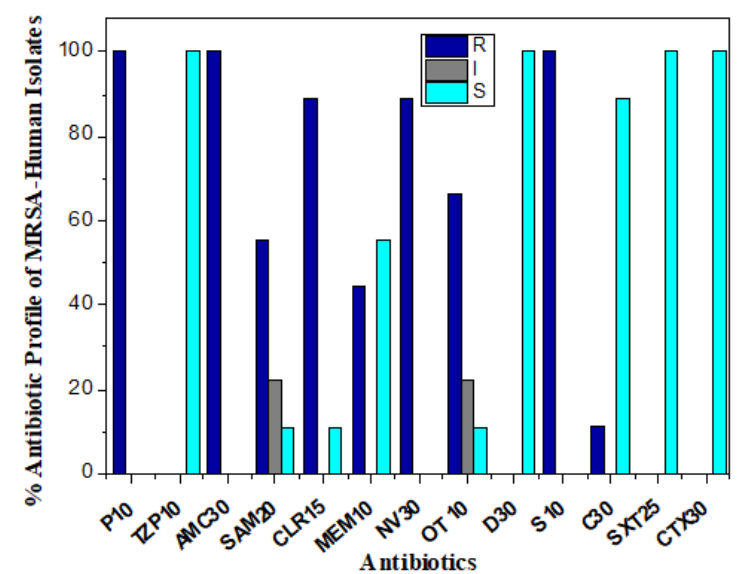

b)

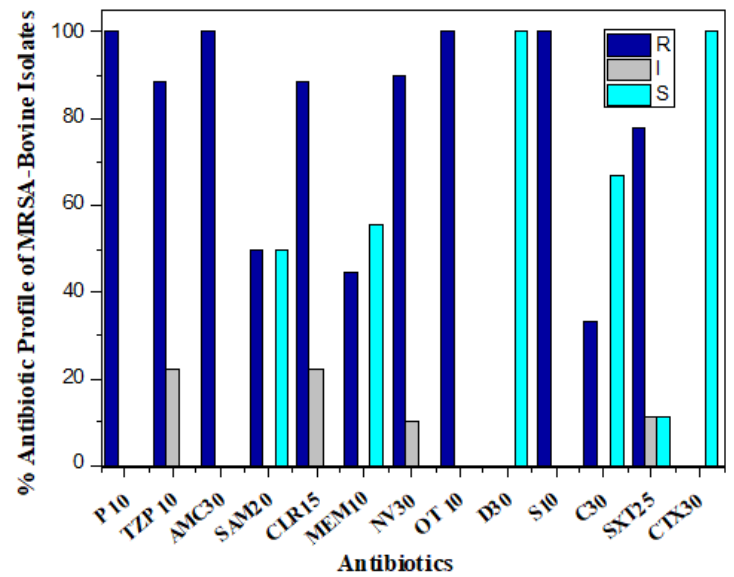

Fig. 2: The antibiotic susceptibility profile of MRSA isolates obtained from a) human, b) bovine milk. The isolates were tested against AMC, amoxicillin-clavulanic acid; SAM20, ampicillin/Sulbactam; C 30, chloramphenicol; NOR10, norfloxacin; NV30, novobiocin; CTX30, Cefotaxime; CLR15, Clarithromycin; S10, streptomycin; MEM10, Meropenem; DA, doxycycline; OT30, tetracycline; SXT25, Trimethoprim/Sulfamethoxazole; R, resistant; I, intermediate; S, susceptible. 
Furthermore, high similarities in resistance of human and bovine isolates were also found with streptomycin (100\%), clarithromycin (88.8\%) and meropenem (44.4\%). No resistance was observed against doxycycline and cefotaxime among bovine and human isolates. A similar high resistance rate was reported with novobiocin among human isolates $(88.8 \%)$ and bovine $(90 \%)$. The variable resistance of human isolates $(66.6 \%)$ and bovine isolates $(100 \%)$ against oxytetracycline was also detected, in addition to, low resistance ranged from $11.1 \%$ in human isolates to 33.3 in bovine isolates against chloramphenicol. However, bovine isolates showed $77 \%$ and $88.8 \%$ resistance against trimethoprim + sulfamethoxazole and piperacillin/tazobactam respectively, on the contrary, human isolates showed $100 \%$ sensitivity to the same antibiotic.

\section{Nucleotide sequencing:}

The mecA gene amplicons ( $310 \mathrm{bp}$ ) of human and bovine MRSA isolates were subjected to partial sequence analysis. The partial meca gene sequences of both human and bovine isolates were submitted to the Genebank database with accession numbers MW715605_M2_Human and W715604_Milk respectively. Partial nucleotide sequences of MRSA mecA genes that generated from the study isolates were firstly compared with published MRSA sequences using BLAST search within the EMBL/GenBank database. The analysis revealed that mecA gene of both human and bovine MRSA isolates had $100 \%$ nucleotide identity with each other and shared 99-100\% nucleotide identity with multiple references MRSA strains of human and animal origin in Genbank database. Nucleotide sequence alignments also revealed that the arrangement patterns of study isolates were identical to various reference MRSA strains. Reference strains used for comparisons comprised of isolates identified previously in Italy (MRSA 350990, 624/I, QXIBV and B1648) as well as MRSA from other countries (e.g. China, USA and Australia).

The phylogenetic analysis of mec a gene sequences generated from both human and bovine milk isolates are typically clustered with MRSA strains in Genbank database including MH798847_350990, KF593809_MRSA_P126, KF234240_R99, HF569114_CMFT532 and HF569111_CMFT489 (Figure 3).

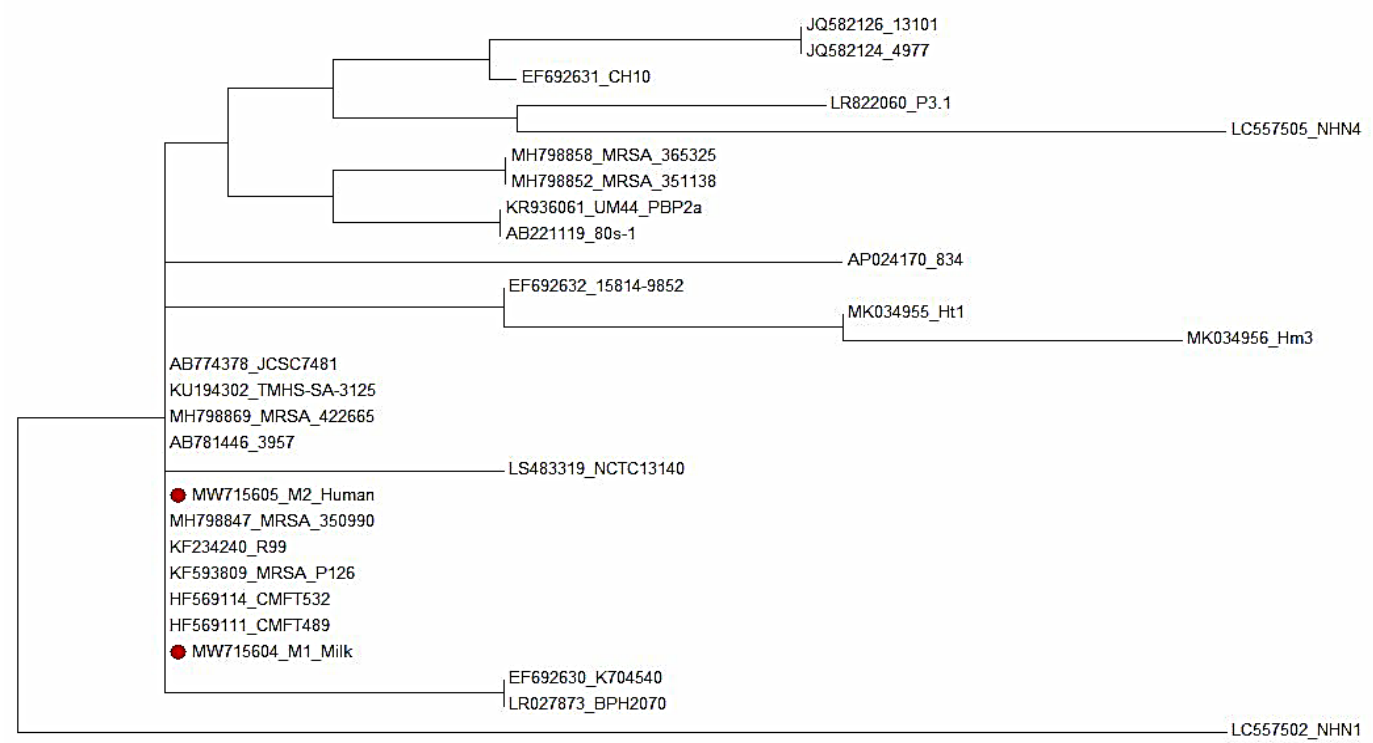

Fig. 3. Phylogenetic tree of study isolates including human MRSA isolate (MW715605_M2_Human and bovine isolate (MW715604_Milk) based on a 310bp fragment of mecA gene sequence.

\section{DISCUSSION}

The growing importance of MRSA is attracting significant epidemiological interest in tracing such strains to picture the distribution of infections in humans and animals and to understand the dynamics of their spread. Here, to describe the prevalence of MRSA and epidemiological relation between isolates from humans and animals in Fayoum city. 50 samples were collected from bulk milk tanks from some villages of Fayoum city and 100 throat swabs from human infected with septic sore throat who live in the same villages. bovine milk and throat swabs were subjected to bacteriological and biochemical analysis. The result detected S. aureus in $74 \%$ (37 isolates) of analyzed bovine milk and $40 \%$ (40 isolates) of human samples respectively. The high prevalence of $S$. aureus in bulk milk tanks, provides evidence of the milked cows were in a phase of subclinical mastitis (da Costa et al., 2016).

Further, the $S$. aureus isolates were subjected to phenotypic and genotypic examination to detect MRSA isolates. Oxacillin disk diffusion method is the major phenotypic method used for MRSA identification and detection of mecA gene or its product (penicillin-binding protein 2a) by molecular methods such as PCR is a golden standard method for confirmation of MRSA isolates (Skov et al., 2006). The result indicated that detection of MRSA using oxacillin disk diffusion method had low sensitivity and is not correlate with the molecular method, which under former studies (Anand et al., 2009; Koupahi et al., 2016). Our study obtained high incidence of MRSA in bovine milk, which is in agreement with various Egyptian studies that documented the MRSA incidence in cattle. For example, El-Ashker et al. (2015) recorded prevalence rate of MRSA (26.5\%) in clinical and subclinical bovine mastitis in Dakahlia city. With regard to incidence of MRSA in human, our data also recorded a high incidence rate in communities other than healthcare communities. Although, MRSA infection has been reported 
previously in Egypt with higher rate in healthcare community than in other communities (Ahmed et al., 2014). Colonization of human with S. aureus and MRSA has been demonstrated worldwide. In United States, a national survey study during 20032004 detected high nasal colonization in human with (29\%) S. aureus and (1.5\%) MRSA (Rachel et al., 2008).

The antibiotics profile of both human and bovine MRSA isolates has shown high degree of similarity, especially in developing resistance to beta-lactams. The beta-lactam antibiotics kill bacteria by disrupting penicillin-binding proteins (PBPs), which are important for synthesis of the bacterial cell wall. PBPs help generate the bacterial cell wall polymer peptidoglycan (PGN), and bind to the glycan filaments in a process called transpeptidation. However, the MRSA mecA gene conferred resistance by encoding peptidoglycan transpeptidase and the penicillin-binding protein $2 \mathrm{a}$, which has a poor affinity for the beta-lactam antibiotic than the original PBPs targeted by these antibiotics (Baek et al., 2014). The observed resistance profile of MRSA strains including resistance to beta-lactams and other antibiotics classes is agreed with Gajdác who reported inactivity of MRSA strains to tetracyclines, fluoroquinolones, aminoglycosides and macrolides besides resistance to betalactam antibiotics (Gajdács, 2019).

In addition to significant similarity in antibiotic profile, the sequence and phylogentic analysis of meca gene produced from human and bovine MRSA isolates revealed high identity. Suggesting that unidirectional transmission of MRSA from human to animal or animal to human. Since the tested humans declared that they had no livestock direct contact, we hypothesized that indirect contact might have happened as they live in villages with high densities of livestock and they may interact indirectly with animals. Our alternative hypothesis suggests that human might be colonized with MRSA due to consumption of raw milk harboring MRSA bacteria. The first hypothesis is in agreement with what already reported in a recent study, demonstrating that adults without professional livestock contacts were found colonized with livestock-associated MRSA strains (Anouk et al., 2020). Another recent study also highlighted the high incidence of MRSA in Shrines environment, where human and primates frequently interact and share antibiotic-resistant bacteria, antibiotic-resistant genes, and diseases (Charu Arjyal et al., 2020).

The power of MRSA strains to adapt to environment and create reservoirs from any host, facilitate their dissemination in a wide scale to include people with no risk for developing infections. Multiple studies isolate MRSA strains from insect and wild animals which have no reasons for antibiotic exposure (Silva et al., 2020). A survey study analyzed stool samples of 2855 wild animals from Germany, Sweden and Austria. The study identified a great diversity of methicillin susceptible and resistant strains from wildlife, with clonal lineages related to humans and animals. Wild birds have been found to carry MRSA strains in Austria (Monecke et al., 2013). Loncaric et al. examined 54 samples from a population of a migratory rook and 102 samples collected from a non-migratory population. The authors reported MRSA strain with mecA gene positivity in five samples of migratory birds, also carrying resistance to different antibiotics classes including ciprofloxacin, tetracycline, aminoglycosides and macrolides (Loncaric et al., 2014). Another study conducted in Austria examined samples from 66 Rattus norvegicus and isolated only one strain harboring mecA gene (Desvars et al., 2016). Insects were also found colonized with MRSA as reported by (Schaumburg et al., 2016). Therefore, the most possible hypothesis is both human and animals acquire infection from different hosts in the environment such as insects or rats. This hypothesis might explain the existence of similar MRSA strains in bovine milk and human with no direct contact with animals.

\section{CONCLUSION}

The present work revealed a significant similarity between meca gene encoding methicillin resistance in $S$. aureus of human origin and meca gene responsible for methicillin resistance in $S$. aureus isolated from bovine milk. In addition, there is a high degree of similarity in antibiotic profiles among isolates from both origins. The data suggesting unidirectional transmission of MRSA between humans and cattle in village of Fayoum city which is an area with dense livestock, where both human and livestock are frequently interacted and may share the antibiotic-resistant bacteria and diseases. Further study is required to expand the investigation to include more villages and to spotlight on the mode of MRSA transmission in the environment, companion animals, livestock and wildlife.

\section{REFERENCES}

Abdel Halium, M. M., Salib, F. A., Marouf, S. A., \& Abdel Massieh, E. S. (2019). Isolation and molecular characterization of Mycoplasma spp. in sheep and goats in Egypt, Veterinary World, 12 (5), 664-670. Abstract.

Anand, K. B., Agrawal, P., Kumar, S., \& Kapila, K. (2009). Comparison of cefoxitin disc diffusion test, oxacillin screen agar, and PCR for mecA gene for detection of MRSA. Indian Journal of Medical Microbiology, 27(1), 27-29.

Arjyal, C., Kc, J., \& Neupane, S. (2020). Prevalence of methicillin-resistant Staphylococcus aureus in shrines. International Journal of Microbiology, 2020.

Bæk, K. T., Gründling, A., Mogensen, R. G., Thøgersen, L., Petersen, A., Paulander, W., \& Frees, D. (2014). $\beta$-Lactam resistance in methicillin-resistant Staphylococcus aureus USA300 is increased by inactivation of the ClpXP protease. Antimicrobial Agents and Chemotherapy, 58(8), 4593-4603.

Bardiau, M., Yamazaki, K., Duprez, J. N., Taminiau, B., Mainil, J. G., \& Ote, I. (2013). Genotypic and phenotypic characterization of methicillin-resistant Staphylococcus aureus (MRSA) isolated from milk of bovine mastitis. Letters in Applied Microbiology, 57(3), 181-186.

Cockerill, F. R., \& Wikler, M. A. (2012). Clinical and Laboratory Standards Institute. Performance standards for antimicrobial susceptibility testing: twenty second informational supplement; [... provides updated tables for... M02-A11 and M07A9].

Da Costa, L. B., Rajala-Schultz, P. J., \& Schuenemann, G. M. (2016). Management practices associated with presence of Staphylococcus aureus in bulk tank milk from Ohio dairy herds. Journal of Dairy Science, 99(2), 1364-1373. 
Desvars-Larrive, A., Ruppitsch, W., Lepuschitz, S., Szostak, M. P., Spergser, J., Feßler, A. T., ... \& Loncaric, I. (2019). Urban brown rats (Rattus norvegicus) as possible source of multidrug-resistant Enterobacteriaceae and meticillin-resistant Staphylococcus spp., Vienna, Austria, 2016 and 2017. Eurosurveillance, 24(32), 1900149.

Dvořák, P., Jahodářová, E., Hašler, P., Gusev, E., \& Poulíčková, A. (2015). A new tropical cyanobacterium Pinocchia polymorpha gen. et sp. nov. derived from the genus Pseudanabaena. Fottea, 15(1), 113-120.

El-Ashker, M., Gwida, M., Tomaso, H., Monecke, S., Ehricht, R., El-Gohary, F., \& Hotzel, H. (2015). Staphylococci in cattle and buffaloes with mastitis in Dakahlia Governorate, Egypt. Journal of Dairy Science, 98(11), 7450-7459.

Gajdács, M. (2019). The continuing threat of methicillin-resistant Staphylococcus aureus. Antibiotics, 8(2), 52.

Gorwitz, R. J., Kruszon-Moran, D., McAllister, S. K., McQuillan, G., McDougal, L. K., Fosheim, G. E., ... \& Kuehnert, M. J. (2008). Changes in the prevalence of nasal colonization with Staphylococcus aureus in the United States, 2001-2004. The Journal of Infectious Diseases, 197(9), 1226-1234.

Haenni, M., Saras, E., Châtre, P., Médaille, C., Bes, M., Madec, J. Y., \& Laurent, F. (2012). A USA300 variant and other humanrelated methicillin-resistant Staphylococcus aureus strains infecting cats and dogs in France. Journal of Antimicrobial Chemotherapy, 67(2), 326-329.

Chudobova, D., Cihalova, K., Guran, R., Dostalova, S., Smerkova, K., Vesely, R., ... \& Kizek, R. (2015). Influence of microbiome species in hard-to-heal wounds on disease severity and treatment duration. Brazilian Journal of Infectious Diseases, 19, 604-613.

Juhász-Kaszanyitzky, É., Jánosi, S., Somogyi, P., Dán, Á., vanderGraaf van Bloois, L., Van Duijkeren, E., \& Wagenaar, J. A. (2007). MRSA transmission between cows and humans. Emerging infectious diseases, 13(4), 630.

Koupahi, H., Jahromy, S. H., \& Rahbar, M. (2016). Evaluation of different phenotypic and genotypic methods for detection of methicillin resistant Staphylococcus aureus (MRSA). Iranian journal of pathology, 11(4), 370.

Kümmel, J., Stessl, B., Gonano, M., Walcher, G., Bereuter, O., Fricker, M., ... \& Ehling-Schulz, M. (2016). Staphylococcus aureus entrance into the dairy chain: tracking S. aureus from dairy cow to cheese. Frontiers in Microbiology, 7, 1603.

Loncaric, I., Stalder, G. L., Mehinagic, K., Rosengarten, R., Hoelzl, F., Knauer, F., \& Walzer, C. (2013). Comparison of ESBL-and $\mathrm{AmpC}$ producing Enterobacteriaceae and methicillin-resistant Staphylococcus aureus (MRSA) isolated from migratory and resident population of rooks (Corvus frugilegus) in Austria. PloS one, 8(12), e84048.

McClure, J. A., Conly, J. M., Lau, V., Elsayed, S., Louie, T., Hutchins, W., \& Zhang, K. (2006). Novel multiplex PCR assay for detection of the staphylococcal virulence marker Panton-Valentine leukocidin genes and simultaneous discrimination of methicillin-susceptible from-resistant staphylococci. Journal of Clinical Microbiology, 44(3), 1141-1144.

Medhus, A., Slettemeås, J. S., Marstein, L., Larssen, K. W., \& Sunde, M. (2013). Methicillin-resistant Staphylococcus aureus with the novel mecC gene variant isolated from a cat suffering from chronic conjunctivitis. Journal of Antimicrobial Chemotherapy, 68(4), 968-969.

Meijs, A. P., Hengeveld, P. D., Dierikx, C. M., Maassen, C. B., de Greeff, S. C., de Haan, A., ... \& van Duijkeren, E. (2020). Prolonged carriage of (livestock-associated) MRSA in individuals without professional livestock contact. Journal of Antimicrobial Chemotherapy, 75(6), 1405-1409.

Monecke, S., Gavier-Widen, D., Mattsson, R., Rangstrup-Christensen, L., Lazaris, A., Coleman, D. C., ... \& Ehricht, R. (2013). Detection of mecC-positive Staphylococcus aureus (CC130-MRSA-XI) in diseased European hedgehogs (Erinaceus europaeus) in Sweden. PloS One, 8(6), e66166.

Schaumburg, F., Onwugamba, F. C., Akulenko, R., Peters, G., Mellmann, A., Köck, R., \& Becker, K. (2016). A geospatial analysis of flies and the spread of antimicrobial resistant bacteria. International Journal of Medical Microbiology, 306(7), 566571.

Schwaber, M. J., Navon-Venezia, S., Masarwa, S., Tirosh-Levy, S., Adler, A., Chmelnitsky, I., ... \& Steinman, A. (2013). Clonal transmission of a rare methicillin-resistant Staphylococcus aureus genotype between horses and staff at a veterinary teaching hospital. Veterinary microbiology, 162(2-4), 907-911.

Silva, V., Capelo, J. L., Igrejas, G., \& Poeta, P. (2020). Molecular epidemiology of Staphylococcus aureus lineages in wild animals in Europe: a review. Antibiotics, 9(3), 122.

Skov, R., Smyth, R., Larsen, A. R., Bolmstrom, A., Karlsson, A., Mills, K., ... \& Kahlmeter, G. (2006). Phenotypic detection of methicillin resistance in Staphylococcus aureus by disk diffusion testing and Etest on Mueller-Hinton agar. Journal of Clinical Microbiology, 44(12), 4395-4399.

Tamura, K., Stecher, G., Peterson, D., Filipski, A. and Kumar, S. (2013): MEGA6: molecular evolutionary genetics analysis version 6.0. Mol. Biol. Evol. 30, 2725-2729.

Thompson, J. D., Higgins, D. G., \& Gibson, T. J. (1994). CLUSTAL W: improving the sensitivity of progressive multiple sequence alignment through sequence weighting, position-specific gap penalties and weight matrix choice. Nucleic acids research, 22(22), 4673-4680.

Vincze, S., Stamm, I., Kopp, P. A., Hermes, J., Adlhoch, C., Semmler, T., ... \& Walther, B. (2014). Alarming proportions of methicillin-resistant Staphylococcus aureus (MRSA) in wound samples from companion animals, Germany 20102012. PloS one, 9(1), e85656.

Walther, B., Wieler, L. H., Vincze, S., Antão, E. M., Brandenburg, A., Stamm, I., ... \& Lübke-Becker, A. (2012). MRSA variant in companion animals. Emerging Infectious Diseases, 18(12), 2017.

Weese, J. S., Caldwell, F., Willey, B. M., Kreiswirth, B. N., McGeer, A., Rousseau, J., \& Low, D. E. (2006). An outbreak of methicillin-resistant Staphylococcus aureus skin infectio1ns resulting from horse to human transmission in a veterinary hospital. Veterinary Microbiology, 114(1-2), 160-164.

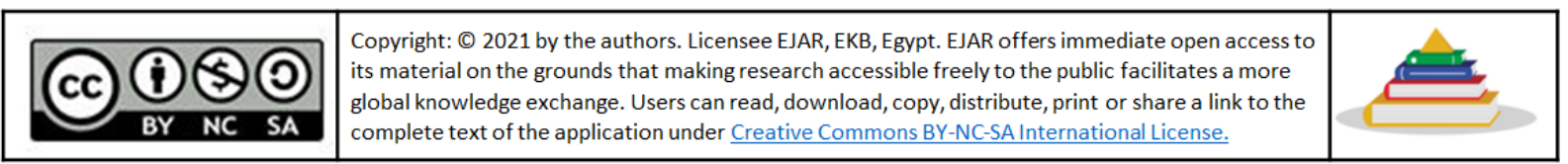




\section{النمط الظاهرية والجينية بين معزولات المكورات العنقودية الذهبية المقاومة للميثيسيلين من الإنسان و حليب الأبقار}

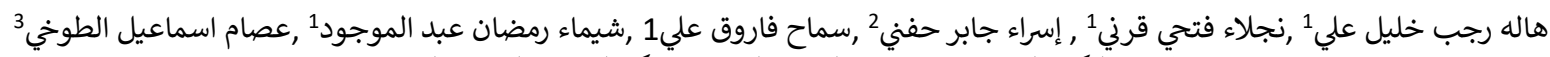

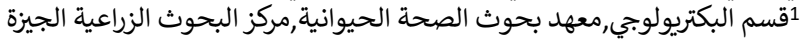

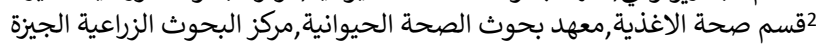

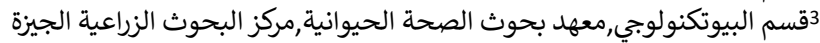
alihala312@gmail.com :برية الرية المؤلف المراسل:

يهدف العمل الحالي إلى تتبع انتشار المكورات العنقودية المقاومة للميثيسيلين في الإنسان وحليب الأبقار في مدينة الفيوم ، مصر.

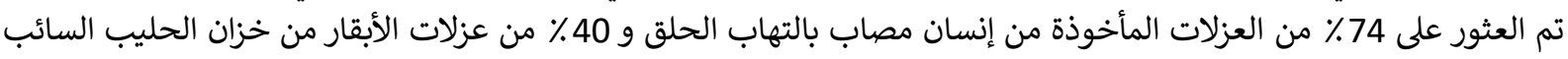

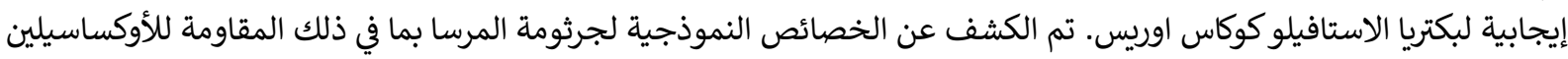
وإيجابية الميكا جين في 8٪ و 7 7

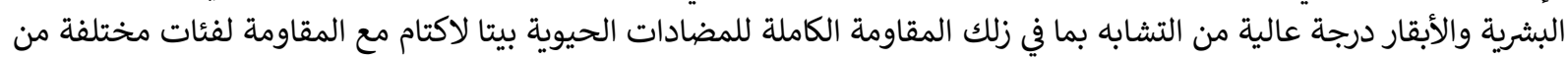

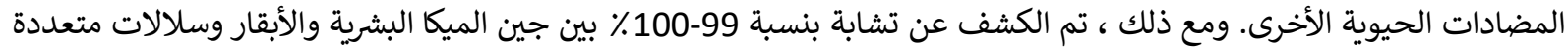

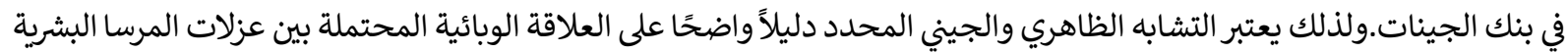

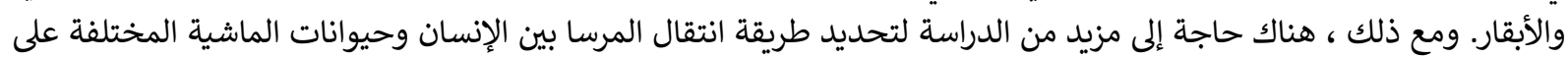
نطاق واسع وتوسيع الدراسة لتشمل الحية الحيوانات منات البرية. الكلمات المفتاحية: المكورات العنقودية المقاومة للميثيسيلين ، التهاب الحلق ، جين الميكا ، خزان الحليب السائب. 